\title{
PEMODELAN REGRESI SPLINE (Studi Kasus: Herpindo Jaya Cabang Ngaliyan)
}

\author{
I Made Budiantara Putra ${ }^{\S 1}$, I Gusti Ayu Made Srinadi ${ }^{2}$, I Wayan Sumarjaya ${ }^{3}$ \\ ${ }^{1}$ Jurusan Matematika, Fakultas MIPA - Universitas Udayana [Email: imadebudiantaraputra@yahoo.co.id] \\ ${ }^{2}$ Jurusan Matematika, Fakultas MIPA - Universitas Udayana [Email: srinadiigustiayumade@yahoo.co.id] \\ ${ }^{3}$ Jurusan Matematika, Fakultas MIPA - Universitas Udayana [Email: sumarjaya@gmail.com] \\ ${ }^{\S}$ Corresponding Author
}

\begin{abstract}
Regression analysis is a method of data analysis to describe the relationship between response variables and predictor variables. There are two approaches to estimating the regression function. They are parametric and nonparametric approaches. The parametric approach is used when the relationship between the predictor variables and the response variables are known or the shape of the regression curve is known. Meanwhile, the nonparametric approach is used when the form of the relationship between the response and predictor variables is unknown or no information about the form of the regression function. The aim of this study are to determine the best spline nonparametric regression model on data of quality of the product, price, and advertising on purchasing decisions of Yamaha motorcycle with optimal knots point and to compare it with the multiple regression linear based on the coefficient of determination $\left(R^{2}\right)$ and mean square error (MSE). Optimal knot points are defined by two point knots. The result of this analysis is that for this data multiple regression linear is better than the spline regression one.
\end{abstract}

Keywords: regression, nonparametric spline, point knot, purchase decision motorcycles Yamaha.

\section{PENDAHULUAN}

Analisis regresi merupakan metode analisis data yang menggambarkan hubungan antara variabel respons dan variabel prediktor (Hosmer dan Lemeshow [5]). Terdapat dua pendekatan untuk mengestimasi fungsi regresi yaitu pendekatan parametrik dan nonparametrik. Pendekatan parametrik yaitu pendekatan yang digunakan apabila bentuk hubungan antara variabel prediktor dan variabel respons diketahui atau bentuk dari kurva regresinya diasumsikan mengikuti pola tertentu. Pendekatan nonparametrik yaitu pendekatan yang digunakan apabila bentuk hubungan antara variabel respons dan prediktornya tidak diketahui atau tidak adanya informasi mengenai bentuk fungsi regresinya. Regresi parametrik memiliki asumsi yang ketat dan kaku seperti sisaan berdistribusi normal dan memiliki varians yang konstan. Selain itu, diketahuinya karakteristik data dari penelitian sebelumnya sangatlah penting agar diperoleh model yang baik. Dalam model regresi parametrik, estimasi kurva regresi ekuivalen dengan estimasi terhadap parameter-parameter dalam model (Budiantara [2]). Untuk menghindari penggunaan asumsi-asumsi yang ketat maka salah satu alternatif yang dapat digunakan adalah dengan pendekatan regresi nonparametrik. Regresi nonparametrik adalah suatu metode pemodelan yang tidak terikat akan asumsi-asumsi dari persamaan regresi tertentu yang memberikan fleksibilitas yang tinggi dalam menduga sebuah model. Beberapa metode estimasi regresi nonparametrik yang dapat digunakan adalah deret Fourier, spline, kernel (Eubank [3]).

Regresi spline adalah suatu metode analisis regresi yang bersifat piecewise polynomial 
yaitu suatu potongan-potongan polinom yang memiliki sifat tersegmen pada selang $k$ yang terbentuk pada titik-titik knot (Wang \& Yang [7]). Titik knot merupakan titik perpaduan bersama yang terjadi karena terdapat perubahan perilaku pola pada interval yang berlainan. Spline mempunyai keunggulan dalam mengatasi pola data yang menunjukkan naik atau turun yang tajam dengan bantuan titik-titik knot, serta kurva yang dihasilkan relatif mulus (Härdle [4]). Estimator spline cenderung mencari sendiri estimasinya kemana pun data tersebut bergerak sehingga memperoleh model yang sesuai dengan bentuk data. Kriteria yang dapat digunakan dalam pemilihan knot yang optimal yaitu Generalized Cross Validation $(G C V)$ (Budiantara [1]).

Data penelitian ini diambil dari penelitian yang dilakukan oleh Nugraha [6] untuk mengetahui faktor-faktor yang memengaruhi keputusan pembelian sepeda motor Yamaha pada Herpindo Jaya cabang Ngaliyan dengan menggunakan analisis regresi berganda dengan variabel respons yaitu keputusan pembelian $(y)$ dan variabel prediktor yaitu kualitas produk $\left(x_{1}\right)$, harga $\left(x_{2}\right)$, dan iklan $\left(x_{3}\right)$. Hasil analisisnya menyatakan bahwa ketiga variabel tersebut merupakan kriteria yang penting bagi pembeli sepeda motor Yamaha di Herpindo Jaya cabang Ngaliyan. Namun hasil dari adjusted $R^{2}$ diperoleh sebesar 0,555 artinya keputusan pembelian terhadap variabel kualitas produk, harga, dan iklan hanya dapat dijelaskan sebesar $55,5 \%$ dari model regresi berganda. Meninjau hasil penelitian yang dilakukan Nugraha [6], maka penulis ingin melanjutkan penelitian tersebut dengan menggunakan analisis regresi spline. Tujuan dari penelitian ini adalah menentukan model regresi spline terbaik pada data kualitas produk, harga, dan iklan terhadap keputusan pembelian sepeda motor Yamaha pada Herpindo Jaya cabang Ngaliyan lalu membandingkannya dengan analisis regresi linier berganda dengan kriteria koefisien determinasi $\left(R^{2}\right)$ yang terbesar dan mean square error (MSE) yang terkecil.

\section{TINJAUAN PUSTAKA}

\section{Analisis Regresi Parametrik}

Analisis regresi merupakan sebuah alat statistika yang digunakan untuk melihat hubungan antara variabel respons dengan satu atau lebih variabel prediktor. Misalkan terdapat data berpasangan $\left(x_{i}, y_{i}\right)$ untuk $n$ pengamatan, maka hubungan antara variabel $x_{i}$ dan variabel $y_{i}$ dapat dinyatakan sebagai berikut:

$$
y_{i}=f\left(x_{i}\right)+\varepsilon_{i} \quad ; \quad i=1,2, \ldots, n(1)
$$

dengan $y_{i}$ adalah respons ke- $i, f\left(x_{i}\right)$ adalah fungsi regresi atau kurva regresi, serta $\varepsilon_{i}$ adalah sisaan yang diasumsikan independent dengan nilai tengah nol dan variansi $\sigma^{2}$.

\section{Analisis Regresi Nonparametrik}

Regresi nonparametrik merupakan suatu metode statistika yang digunakan untuk mengetahui pola hubungan antara variabel prediktor dengan respons ketika tidak diperoleh informasi sebelumnya tentang bentuk fungsi regresinya atau tidak diketahui bentuk kurva regresinya. Fungsi dari model regresi nonparametrik dapat berbentuk apa saja, baik linear atau nonlinear. Misalkan variabel respons adalah $y$ dan variabel prediktor adalah $x$ untuk $n$ pengamatan, model umum dari regresi nonparametrik adalah $y_{i}=f\left(x_{i}\right)+\varepsilon_{i} ; i=$ $1,2,3, \ldots, n$

dengan $y_{i}$ adalah variabel respons, $x_{i}$ adalah variabel prediktor, $f\left(x_{i}\right)$ adalah fungsi regresi yang tidak diketahui bentuknya, dan $\varepsilon_{i}$ adalah sisaan yang diasumsikan bebas dengan nilai tengah nol dan varians $\sigma^{2}$.

\section{Analisis Regresi Spline}

Spline merupakan model polinom yang tersegmen atau terpotong-potong yang mulus dan dapat menghasilkan fungsi regresi yang sesuai dengan data. Mengestimasi spline tergantung pada titik knot. Titik knot merupakan suatu titik perpaduan yang terjadi karena perubahan pola perilaku dari suatu fungsi pada selang yang berbeda. Fungsi spline pada suatu fungsi $f$ dengan orde $p$ dapat dinyatakan sebagai berikut:

$f\left(x_{i}\right)=\sum_{j=0}^{p} \beta_{j} x_{i}^{j}+\sum_{l=1}^{r} \beta_{(p+l)}\left(x_{i}-k_{l}\right)_{+}^{p}(3)$ dengan $k$ menyatakan banyaknya titik knot dan $\left(x_{i}-k_{l}\right)_{+}^{p}$ menyatakan fungsi potongan 
(truncated) yang dapat djabarkan sebagai berikut:

$\left(x_{i}-k_{l}\right)_{+}^{p}=\left\{\begin{array}{c}\left(x_{i}-k_{l}\right)^{p}, \quad x_{i} \geq k_{l} \\ 0, \quad x_{i}<k_{l}\end{array}\right.$

Bentuk matematis dari fungsi spline pada persamaan (3), dapat dinyatakan bahwa spline adalah potongan-potongan polinom yang berbeda digabungkan bersama titik knot $k_{1}, k_{2}, k_{3}, \ldots, k_{r}$ untuk menjamin sifat kontinuitasnya. Model regresi spline dapat pula disajikan dalam bentuk matriks yang dituliskan sebagai berikut:

$$
\begin{aligned}
& {\left[\begin{array}{c}
f\left(x_{1}\right) \\
f\left(x_{2}\right) \\
f\left(x_{3}\right) \\
\vdots \\
f\left(x_{n}\right)
\end{array}\right]==0} \\
& {\left[\begin{array}{cccccccc}
1 & x_{1}^{1} & x_{1}^{2} & \ldots & x_{1}^{p} & \left(x_{1}-k_{1}\right)_{+}^{p} & \ldots & \left(x_{1}-k_{r}\right)_{+}^{p} \\
1 & x_{2}^{1} & x_{2}^{2} & \ldots & x_{2}^{p} & \left(x_{2}-k_{1}\right)_{+}^{p} & \ldots & \left(x_{2}-k_{r}\right)_{+}^{p} \\
1 & x_{3}^{1} & x_{3}^{2} & \ldots & x_{3}^{p} & \left(x_{3}-k_{1}\right)_{+}^{p} & \ldots & \left(x_{3}-k_{r}\right)_{+}^{p} \\
1 & & \beta_{0} & & & \\
\beta_{0} \\
\beta_{1} \\
\beta_{3} \\
\vdots \\
\beta_{p} \\
\beta_{(p+1)} \\
\vdots \\
\beta_{(p+r)}
\end{array}\right]}
\end{aligned}
$$
atau$$
f(x)=x \beta
$$

Estimasi regresi nonparametrik spline diperoleh dengan menggunakan metode Maximum Likelihood Estimator (MLE). Jika error pada persamaan (2) diasumsikan berdistribusi normal, maka $y_{i}$ juga berdistribusi normal dengan nilai tengah $f\left(x_{i}\right)$ dan varians $\sigma^{2}$. Sehingga fungsi densitas peluang $y_{i}$ menjadi

$f\left(y ; f(x), \sigma^{2}\right)=$

$\frac{1}{\sqrt{2 \pi \sigma^{2}}} \exp \left[-\frac{(y-f(x))^{2}}{2 \sigma^{2}}\right], f(x)>0, \sigma^{2}>0(6)$

Fungsi likelihood dapat dituliskan sebagai berikut:

$$
\begin{array}{r}
L(y, f)=\prod_{i=1}^{n} f\left(y_{i} ; f\left(x_{i}\right), \sigma^{2}\right) \\
=\left(2 \pi \sigma^{2}\right)^{-n / 2} \exp \left[-\frac{1}{2 \sigma^{2}} \sum_{i=1}^{n}\left(y_{i}-\right.\right. \\
\left.\left.f\left(x_{i}\right)\right)^{2}\right] .(7)
\end{array}
$$

Estimasi titik fungsi $f$ diperoleh dengan memaksimumkan fungsi likelihood $L(y, f)$ yang dapat diuraikan sebagai berikut:

$$
\begin{aligned}
& \max _{f}\{L(y, f)\}= \\
& \max _{\beta \varepsilon R^{p+r}}\left\{( 2 \pi \sigma ^ { 2 } ) ^ { - \frac { n } { 2 } } \operatorname { e x p } \left(-\frac{1}{2 \sigma^{2}} \sum_{i=1}^{n}\left(y_{i}-\right.\right.\right. \\
& \left.\left.\left.\left(\sum_{j=1}^{p} \beta_{j} x_{i}^{j}+\sum_{l=1}^{r} \beta_{p+l}\left(x_{i}-k_{l}\right)_{+}^{p}\right)\right)\right)^{2}\right\}
\end{aligned}
$$

Apabila optimasi ini diselesaikan akan diperoleh estimator untuk $\beta$ adalah:

$$
\widehat{\boldsymbol{\beta}}=\left(\boldsymbol{x}^{\prime} \boldsymbol{x}\right)^{-\mathbf{1}} \boldsymbol{x}^{\prime} \boldsymbol{y} .
$$

Estimasi dari $\hat{y}$ dapat dituliskan sebagai berikut:

$$
\begin{gathered}
\widehat{y}=x \widehat{\beta} \\
\hat{y}=x\left(x^{\prime} x\right)^{-1} x^{\prime} y=A(k) y
\end{gathered}
$$

dengan $\boldsymbol{A}(\boldsymbol{k})$ merupakan matriks yang digunakan untuk perhitungan pada rumus GCV dalam pemilihan titik knot optimal.

\section{Pemilihan Titik Knot Optimal}

Pemilihan estimator regresi spline terbaik diantara model-model yang didapatkan dilihat berdasarkan kriteria Generalized Cross Validation (GCV) yang minimum. Rumus untuk menghitung GCV adalah sebagai berikut:

$$
G C V(k)=\frac{M S E(k)}{\left(n^{-1} \operatorname{tr}[I-A(k)]\right)^{2}}
$$

dengan $\operatorname{MSE}(k)=n^{-1} \sum_{i=1}^{n}\left(y_{i}-\hat{y}\right)^{2}, \quad n$ adalah jumlah data, $I$ adalah matriks identitas, $k$ adalah titik knot $\left(k_{1}, k_{2}, k_{3}, \ldots, k_{n}\right)$, dan $A(k)=x\left(x^{\prime} x\right)^{-1} x^{\prime}$.

\section{METODE PENELITIAN}

Data yang digunakan dalam penelitian ini adalah data sekunder yang diambil dari penelitian Nugraha [6], penelitian tersebut membahas analisis pengaruh kualitas produk, harga, dan iklan terhadap keputusan pembelian sepeda motor Yamaha pada Harpindo Jaya cabang Ngalian. Variabel-variabel tersebut diukur menggunakan skala Likert. Penelitian yang dilakukan oleh Nugraha [6], untuk mendapatkan nilai pada setiap variabel dilakukan dengan menjumlahkan skor dari setiap pertanyaan yang menyusun masingmasing variabel. Pada penelitian ini, variabelvariabel yang digunakan adalah skor faktor dari indikator/pertanyaan penyusunnya.

Langkah-langkah yang dilakukan dalam penelitian ini adalah sebagai berikut: (a) memodelkan variabel respon dan prediktor dengan regresi nonparametrik spline dengan satu knot, dua knot, tiga knot, empat knot, dan lima knot, dan memilih titik knot optimal 
berdasarkan kriteria GCV yang paling minimum, (b) melakukan perbandingan antara regresi spline dan regresi linier berganda berdasarkan kriteria $R^{2}$ dan MSE.

\section{HASIL DAN PEMBAHASAN}

\section{Penentuan Model Regresi Spline yang Terbaik}

Pemilihan model regresi spline yang terbaik dipilih berdasarkan lokasi dan banyaknya titik knot. Dalam memilihan titik knot yang optimal sangatlah penting dalam menentukan model terbaik. Lokasi titik knot yang berbeda akan mengkasilkan model yang berbeda. Titik knot yang optimal dilihat berdasarkan kriteria GCV yang paling minimum. Berikut ini merupakan tabel yang menunjukan titik-titik knot yang optimal, GCV yang minimum, dan orde yang optimal pada setiap variabel.

Tabel 1. Nilai GCV Minimum untuk MasingMasing Titik Knot

\begin{tabular}{|c|c|c|c|l|}
\hline \multirow{2}{*}{ knot } & \multicolumn{3}{|l|}{ Orde } & \multirow{2}{*}{ GCV } \\
\cline { 2 - 4 } & $x_{1}$ & $x_{2}$ & $x_{3}$ & \\
\hline 1 & 2 & 2 & 2 & 0,771588 \\
\hline $\mathbf{2}$ & $\mathbf{2}$ & $\mathbf{2}$ & $\mathbf{2}$ & $\mathbf{0 , 7 3 0 9 3}$ \\
\hline 3 & 2 & 2 & 2 & 0,73769 \\
\hline 4 & 3 & 3 & 3 & 0,76741 \\
\hline 5 & 3 & 3 & 3 & 0,80233 \\
\hline
\end{tabular}

Bedasarkan Tabel 1, dapat dilihat bahwa nilai GCV minimum diperoleh untuk model dengan dua titik knot. Titik knot pada $x_{1}$ adalah 2,24862 dan 1,7902, pada $x_{2}$ adalah $-2,087$ dan 1,20372, yang terakhir $x_{3}$ adalah -2,21701 dan 2,01696. Estimasi model regresi spline dengan dua titik knot dapat dilihat pada Tabel 2.

Sehingga model terbaik untuk pengaruh kualitas produk, harga, dan iklan terhadap keputusan pembelian sepeda motor Yamaha menggunakan dua titik knot. Berikut merupakan persamaan model regresi nonparametrik spline dengan dua titik knot.

$$
\begin{aligned}
\hat{y}=0,49562 x_{1}+ & 0,15367 x_{1}^{2} \\
& -0,02524\left(x_{1}-(-2,24862)\right)_{+}^{2} \\
& +0,0319\left(x_{1}-1,7902\right)_{+}^{2} \\
& +0,34023 x_{2}-0,11719 x_{2}^{2} \\
& +0,07506\left(x_{2}-(-2,087)\right)_{+}^{2} \\
& +2,328\left(x_{2}-1,20372\right)_{+}^{2} \\
& -0,24392 x_{3}+0,03027 x_{3}^{2} \\
& -0,05981\left(x_{3}-(-2,21701)\right)_{+}^{2} \\
& +1,77059\left(x_{3}-2,01696\right)_{+}^{2} .
\end{aligned}
$$

Tabel 2. Estimasi Model Regresi Spline dengan dua Titik Knot

\begin{tabular}{|c|l|}
\hline Parameter & \multicolumn{1}{|c|}{ Estimasi } \\
\hline$\beta_{1}$ & 0.49562 \\
\hline$\beta_{2}$ & 0.15367 \\
\hline$\beta_{3}$ & -0.02524 \\
\hline$\beta_{4}$ & 0.0319 \\
\hline$\beta_{5}$ & 0.34023 \\
\hline$\beta_{6}$ & -0.11719 \\
\hline$\beta_{7}$ & 0.07506 \\
\hline$\beta_{8}$ & 2.328 \\
\hline$\beta_{9}$ & -0.24392 \\
\hline$\beta_{10}$ & 0.03027 \\
\hline$\beta_{11}$ & -0.05981 \\
\hline$\beta_{12}$ & 1.77059 \\
\hline
\end{tabular}

\section{Perbandingan Antara Analisis Regresi Linier Berganda dengan Regresi Spline}

Perbandingan antara regresi linier berganda dengan regresi spline dapat dilihat dari hasil nilai koefisien determinasi $\left(R^{2}\right)$ yang lebih besar nilainya dan Mean Square Error (MSE) yang paling minimum. Berikut ini merupakan tabel perbandingan nilai koefisien determinasi $\left(R^{2}\right)$ dan Mean Square Error (MSE) terhadap regresi berganda dan regresi spline.

Tabel 3. Perbandingan Analisis Regresi Berganda dengan Regresi Spline

\begin{tabular}{|l|l|l|}
\hline & $R^{2}$ & MSE \\
\hline Regresi Berganda & $53,1 \%$ & 0,469 \\
\hline Regresi Spline & $36,06 \%$ & 0,645 \\
\hline
\end{tabular}

Berdasarkan Tabel 3 koefisien determinasi regresi spline nilainya lebih kecil dari regresi linier berganda dan juga nilai MSE dari regresi spline lebih besar dari regresi linier berganda. Pada data ini, model regresi berganda lebih baik dari pada regresi spline karena koefisien data regresi spline lebih kecil dari pada regresi linier berganda. Artinya keputusan pembelian 
sepeda motor Yamaha dapat dijelaskan sebesar $53,1 \%$ oleh variabel kualitas produk, harga dan iklan dengan regresi linier berganda sedangkan 36,06\% dengan regresi spline. Nilai MSE dari regresi linier berganda pada data ini lebih baik dari regresi spline karena nilai MSE regresi linier berganda lebih kecil dari regresi spline. Artinya tingkat kesalahan pada model regresi linier berganda lebih kecil dari regresi spline atau pengukuran yang dilakukan regresi linier berganda lebih teliti dari pada regresi spline.

\section{KESIMPULAN DAN SARAN}

Berdasarkan hasil pembahasan, maka diperoleh kesimpulan bahwa model regresi nonparametrik spline yang terbaik adalah model regresi spline dengan dua titik knot. Nilai GCV yang dihasilkan adalah 0,73093. Model regresi nonparametrik spline adalah sebagai berikut.

$$
\begin{aligned}
\hat{y}=0,49562 x_{1}+ & 0,15367 x_{1}^{2} \\
& -0,02524\left(x_{1}-(-2,24862)\right)_{+}^{2} \\
& +0,0319\left(x_{1}-1,7902\right)_{+}^{2} \\
& +0,34023 x_{2}-0,11719 x_{2}^{2} \\
& +0,07506\left(x_{2}-(-2,087)\right)_{+}^{2} \\
& +2,328\left(x_{2}-1,20372\right)_{+}^{2} \\
& -0,24392 x_{3}+0,03027 x_{3}^{2} \\
& -0,05981\left(x_{3}-(-2,21701)\right)_{+}^{2} \\
& +1,77059\left(x_{3}-2,01696\right)_{+}^{2} .
\end{aligned}
$$

Berdasarkan perbandingan nilai koefisien determinasi $\left(R^{2}\right)$ dan Mean Square Error (MSE) antara analisis regresi spline dan regresi linier berganda pada data pengaruh kualitas produk, harga dan iklan terhadap keputusan pembelian sepeda motor Yamaha menunjukkan bahwa regresi linier berganda lebih baik dari regresi spline karena koefisien determinasi regresi linier berganda lebih besar dari regresi spline dan nilai MSE dari regresi berganda lebih kecil dari regresi spline.

Untuk penelitian selanjutnya saran yang dapat penulis sampaikan adalah sebuah model pada regresi spline multivariabel, orde pada setiap variabel tidak harus sama melainkan bisa berbeda-beda untuk setiap variabel. Dan apabila ingin menggunakan data penelitian ini disarankan untuk menambahkan indikator lain yang belum dimasukan dalam model.

\section{DAFTAR PUSTAKA}

[1] Budiantara, I. N. 2000. Metode U, GML, CV, dan GCV dalam Regresi Nonparametrik Spline.Majalah Ilmiah Himpunan Matematika Indonesia (MIHMI), Vol. 6, 285-290.

[2] ,2009. Spline dalam Regresi

Nonparametrik dan Semiparametrik: Sebuah Pemodelan Statistika Masa Kini dan Masa Mendatang. Pidato Pengukuhan Untuk Jabatan Guru Besar Dalam Bidang Ilmu Matematika Statistika dan Probabilitas, Pada Jurusan Statistika, Fakultas MIPA. Institut Teknologi Sepuluh Nopember, ITS Press: Surabaya.

[3] Eubank, R. 1988. Spline Smoothing and Nonparametric Regression. Marcel Dekker. New York.

[4] Härdle, W. 1990.Applied Nonparametric Regression. Cambridge University Press, New York.

[5] Hosmer, D.W. and S. Lemeshow. 2000. Applied Logistic Regression, second edition. John Wiley and Sons, Inc. New York.

[6] Nugraha. M. N. S. 2010. Analisis Pengaruh Kualitas Produk, Harga, dan Iklan Terhadap Keputusan Pembelian Sepeda Motor Yamaha pada Harpindo Jaya Cabang Ngaliyan. Skripsi. Jurusan Manajemen Fakultas Ekonomi Universitas Diponegoro, Semarang.

[7] Wang, J. and Yang, L. 2009. Polynomial Spline Confidence Bands for Regression Curves. Statistica Sinica. 19: 325-342. 